\title{
Markov chain analysis of the rainfall patterns of five geographical locations in the south eastern coast of Ghana
}

\author{
Meshach Tettey ${ }^{1,2}$, Francis T. Oduro ${ }^{1}$, David Adedia ${ }^{3}$ and Daniel A. Abaye ${ }^{3^{*}}$
}

\begin{abstract}
This study develops an objective rainfall pattern assessment through Markov chain analysis using daily rainfall data from 1980 to 2010, a period of 30 years, for five cities or towns along the south eastern coastal belt of Ghana; Cape Coast, Accra, Akuse, Akatsi and Keta. Transition matrices were computed for each town and each month using the conditional probability of rain or no rain on a particular day given that it rained or did not rain on the previous day. The steady state transition matrices and the steady state probability vectors were also computed for each town and each month. It was found that, the rainy or dry season pattern observed using the monthly steady state rainfall vectors tended to reflect the monthly rainfall time series trajectory. Overall, the probability of rain on any day was low to average: Keta 0.227, Akuse 0.382, Accra 0.467, Cape Coast, 0.50 and Akatsi 0.50. In particular, for Accra, the rainy season was observed to be in the months of May to June and September to October. We also determined that the probability of rainfall generally tended to increase from east to west along the south eastern coast of Ghana.
\end{abstract}

Keywords: Markov chain analysis, Transition state matrix, Rainfall prediction, Probability of rain or dry, South Eastern Coast of Ghana

\section{Background}

Global warming has been confirmed to be affecting regional and continental rainfall patterns of the world, with the recorded evidence showing that there is an increase in precipitation in Canada, northern Europe and northern Russia, while vast areas of sub-Saharan Africa, southern India and South-East Asia are becoming dryer (Groisman et al. 2005; Kharin et al. 2005; Westral et al. 2013; Fletcher et al. 2015). Changes in precipitation patterns have significant effects on ecosystems, agriculture and human regions that are sensitive to changes in precipitation, such as the Sahel (Groisman et al. 2005; Dore, 2005; IPCC 2014). Precipitation patterns are certain to be affected by global warming, because air and sea temperatures and sea-level atmospheric pressure, which are the underlying forces behind these patterns, are already changing. However, until the beginning of the twenty-first Century, there was little observable evidence to support this interference

\footnotetext{
* Correspondence: dabaye@uhas.edu.gh

${ }^{3}$ School of Basic and Biomedical Sciences, University of Health and Allied

Sciences, PMB, $31 \mathrm{Ho}, \mathrm{VR}$, Ghana

Full list of author information is available at the end of the article
}

or changes in rainfall patterns. Most reports were either anecdotal or in computer models, rather than from observation. One problem for researchers has been lack of accurate, long-term rainfall data from around the world that would enable them to distinguish between regional or cyclical shifts in rainfall patterns.

In their seminal work, von Storch and Zwiers (1999) analysed two data-sets of global rainfall patterns covering the years 1925 to 1999 . A comparison was made between their data and that of 14 powerful computer models that simulate the world's climate systems and found a remarkably close fit. Their work concluded that, over the 75-year period under study, global warming 'contributed significantly' to increases in precipitation in the northern hemisphere's mid-latitudes, a region between $40^{\circ}$ and $70^{\circ}$ north. In contrast, the northern hemisphere's tropics and subtropics, a region spanning from the Equator to $30^{\circ}$ north, became drier. These trends have since been confirmed by many other reports (e.g. Groisman et al. 2005; Westra et al. 2013; IPCC, 2014). Nevertheless, torrential rains have continued to deluge locations in these drier zones including Accra, Ghana's capital creating floods 
in various parts that have caused great havoc to property and loss of lives, on 22 June 2010 (Coffie, 2010). In the first two decades of the twenty-first century, such scenes have been repeated across all continents.

Ghana is one of the countries in the world whose economy is highly dependent on rain-fed agriculture. Ghana is experiencing increasing temperatures and unpredictable rainfall patterns (EPA, Ghana 2000; Nelson and Agbey, 2005). This has led to the National Meteorological Services Agency of Ghana (NMSAG http://www.meteo.gov.gh/website/\#) actively participating in the National Early Warning System aimed at mitigating the effects of natural disasters, including drought and flooding. But the role of the Agency will be more beneficial if the information it provides is updated regularly by monitoring, recording and analysis of the accurate and reliable data and their publications to the relevant national bodies.

Ghana is located within the tropical region. It is therefore, influenced by weather systems of various scales, from mesoscale, such as thunderstorms, to large-scale El Nino Southern Oscillation (ENSO) related phenomena (e.g. Cai et al. 2015). The major rain-bearing system for the main rainy season (June to September) is the Inter Tropical Convergence Zone (ITCZ). On the other hand, the eastward moving mid-latitude troughs will facilitate the interaction between the mid-latitude cold air and the tropical warm air so that unstable conditions will be created for the moisture that comes into Ghana from the Atlantic ocean during the small rainy season (February to May; Climate Change Knowledge Portal).

Recent advances in the application of statistical methods have dramatically improved the range of techniques available for analyzing data that are not from normal distribution. One of these applications, Markov chain analysis, which is used in this study, parallel those used in the analysis of variance (ANOVA) and regression for normally distributed data. This development is of considerable importance, since daily rainfalls are clearly not normally distributed (Stern and Coe, 1984). The amount of rain, intensity, duration and frequency inevitably impact on all activities that determine crop production and also influence the socio-economic texture of the communities and countries world-wide. A mean temperature change of $1{ }^{\circ} \mathrm{C}$ near the earth's surface leads to large changes in rainfall patterns (Hansen et al. 2010). With the development of industrialization and the rapid growth of population, the management of water resources is becoming more important not only in Ghana but throughout the world.

The analysis of precipitation patterns behavior particularly in terms of amount of rainfall, frequency, intensity, duration and distribution, is beneficial for managing the consumption of water. Rain plays a major role in hydrology that finds its greatest applications in the design and operations of water resources, engineering works as well as agricultural systems (Srikanthan and McMahon, 2005). Quantification of rainfall is generally done by using pluvial maps and Intensity-DurationFrequency (IDF) curves (Raiford et al. 2007). A more recent interest in rainfall modeling is the perspective of using model parameters to characterize changes in the precipitation patterns because of the greenhouse effect and climate change. Available models have been linked to the temporal and spatial scale required for the analysis. In the empirical case, there is no attempt to incorporate physical modeling of the atmosphere but to the empirical stochastic models to the available data.

The probability estimation for rainfall states from available time series helps to obtain predictions for rainfall statistical parameters such as the averages, standard deviations and the first order autocorrelation coefficient. The transition probability estimations between the states of successive time instances are necessary for model construction. Also, theoretical Weibull, Gamma, Extreme Value Distribution functions are used most often in practice and for predicting the magnitude of rainfall (Villarini et al. 2010; Papalexiou et al. 2013). For accounting dependency in any time series, often a first order Markov Chain is used for modeling. For instance, large variety of weather events modeling and simulation (Gringorten, 1996) and long time series of weather data generations (Racsko et al. 1991) were studied through Markov Chain. For rainfall data, many authors have demonstrated that Markov Chain model can be used to synthesize rainfall time series (Haan et al. 1976; Wilks and Wilby, 1999; Gregory et al. 1993; Robertson et al. 2004; Paulo and Pereira, 2007).

The study on the sequence of daily rainfall occurrence was initiated by Gabriel and Neumann (1962). They demonstrated that the daily rainfall occurrence for the Tel Aviv, Israel data was successfully fitted with the first-order Markov chain model. Much later, other studies also reported that the first order of the Markov chain model was found to fit the observed data in Italy successfully (Kottegoda et al. 2004). The model is based on the assumption that there is a dependency of the daily rainfall occurrence to that of the previous day. One of the most attractive features of the Markov chain model involved providing the ease in identifying the seasonality in daily rainfall occurrence and in most cases, the Markov chain of the first-order model can describe the daily rainfall occurrence (Stern and Coe 1984); however, there are cases where this model failed to fit the observed data. As an alternative, the use of the Markov chain model of higher orders often improved these inadequacies (Wilks, 1999; Hayhoe, 2000). 


\section{Aims}

The recent change in climatic patterns is of major concern and has led to disasters in various parts of the world including Ghana. Hence, in this report, we set out to model rainfall patterns using rainfall data in order to determine the rainy or dry seasons in the selected area under investigation. The sub-objectives of the report are three-fold; 1 , to modeling the rainfall pattern in south eastern coast of Ghana using Markov chain analysis, 2, to determine the positions of rainy or dry seasons within the year in five selected meteorological stations and, 3, to make recommendations for agricultural and commercial applications in south eastern coast of Ghana. The information on the wet and dry patterns has vital importance to all allied fields like agriculture, industry and insurance etc. Once the rainfall process is adequately and appropriately modeled, the model can then be used in agricultural planning, aid in predicting periods of drought, soil erosion and flooding. The model can also be extended to assess the impact of climate change on relatively small geographical areas, rainfall runoff modeling, crop growth studies and other important fields. A literature search showed that a number of global precipitation datasets which also cover Ghana exist. For example, the University of California Irvine Center for Hydrometeorology and Remote Sensing (CHRS) using remotely sensed data (https://www.ncdc.noaa.gov/cdr/ atmospheric/precipitation-persiann-cdr). Their data covered the years 1983 to near-present. However, no publication of rainfall patterns in Ghana using Markov chain analysis has been published from within Ghana.

\section{Methodology}

\section{Markov Chain Model}

A Markov chain or Markov process, named after Russian mathematician, Andrey Markov (Shannon, 1948), is a mathematical system that undergoes transitions from one state to another (from a finite or countable number of possible states) in a chain like manner. It is a random process endowed with the Markov property. The Markov property states that the conditional probability distribution for a system at the next step given its current state depends only on the current state of the system, and not additionally on the state of the system at previous steps. Since the system changes randomly, it is generally impossible to predict the exact state of the system in the future.

Usually, a Markov chain would be defined for a discrete set of times (i.e. a discrete-time Markov chain) although some authors use the same terminology where 'time' can take continuous values. The use of the term in Markov chain Monte Carlo methodology covers cases where the process is in discrete-time (discrete algorithm steps) with a continuous state-space. The following concentrates on the discrete-time with discrete-state-space case.
A 'discrete-time' random process means a system which is in a certain state at each 'step', with the state changing randomly between steps. The steps are often thought of as time, but they can equally well refer to physical distance or any other discrete measurement; formally, the steps are just the integers or natural numbers, and the random process is a mapping of these two states, that is, discrete-time with discrete-state-space and discrete-time with a continuous state-space. Since the system changes randomly, it is generally impossible to predict the exact state of the system in the future. However, the statistical properties of the system's future can be predicted. In many applications it is these statistical properties that are important. The changes of state of the system are called transitions, and the probabilities associated with various state-changes are called transition probabilities. The set of all states and transition probabilities completely characterizes a Markov chain. By convention, we assume all possible states and transitions have been included in the definition of the processes, so there is always a next-state and the process goes on forever.

Markov chain has been widely applied in the disciplines of natural science, engineering, economics and management (Liu et al. 2009). The Markov chain modeling approach is useful in understanding the stochastic characteristics of droughts and rainfall through the analysis of probabilities for each severity class, times for reaching the non-drought class from any drought severity state, and residence times in each drought class (Paulo and Pereira, 2007). The approach can be satisfactorily used as a predictive tool for forecasting transitions among drought severity classes up to 3 months ahead (Paulo and Pereira, 2007). An early warning system for drought management was developed using the Markov chain, in two climatic areas of Virginia, USA (Lohani and Loganathan, 1997; Lohani et al. 1998). Liu et al. (2009) demonstrated two advantages of the Markov chain technique for forecasting drought and rainfall conditions. They were: 1 , the predictive performance increased greatly as the severity of drought increased, and 2, the predictive performance was always satisfactory for drought state transitions, and the prediction performance was acceptable for the successive and smooth states. The analysis of daily rainfall data shows that Markov Chain approach provides one alternative to modeling future variation in rainfall. These variations may either be in the form of too much water, which will lead to flooding or too little water, which will lead to drought. Markov modeling is one of the tools that can be utilized to assist planners in assessing the rainfall patterns; frequency, duration, intensity and distribution. 


\section{Markov chain modeling}

The Markov chain model is explained as follows:

The probability of going from state $i$ to state $j$ in $n$ time steps is given as

$$
P_{i j}^{(n)}=\operatorname{Pr}\left(X_{n}=j \mid X_{0}=i\right)
$$

and the single-step transition is

$$
P_{i j}=\operatorname{Pr}\left(X_{1}=j \mid X_{0}=i\right) .
$$

For a time-homogeneous Markov chain:

$$
P_{i j}^{(n)}=\operatorname{Pr}\left(X_{k+n}=j \mid X_{k}=i\right)
$$

and

$$
P_{i j}=\operatorname{Pr}\left(X_{k+1}=j \mid X_{k}=i\right) .
$$

The $n$-step transition probabilities satisfy the Chapman-Kolmogorov equation (Papoulis, 1984), that for any $k$ such that $0<k<n$,

$$
P_{i j}^{(n)}=\sum_{r \in S} P_{i r}^{(k)} P_{r j}^{(n-k)}
$$

Where, $S$ is the state space of the Markov chain.

The marginal distribution $\operatorname{Pr}\left(X_{n}=x\right)$ is the distribution over states at time $n$. The initial distribution is $\operatorname{Pr}\left(X_{0}=x\right)$. The evolution of the process through one time step is described by

$$
\begin{aligned}
\operatorname{Pr} & =\left(X_{n}=j\right)=\sum_{r \in S} P_{r j} \operatorname{Pr}\left(X_{n-1}=r\right) \\
& =\sum_{r \in S} P_{r j}^{(n)} \operatorname{Pr}\left(X_{0}=r\right) .
\end{aligned}
$$

The $(i, j) t h$ element of the matrix product $p^{n-1} \cdot p=p^{n}$, which confirms $p^{(n)}=p^{n}$. The result $p^{(n)}=p^{(0)} p^{n}$ is obtained by noting that

$$
p\left(X_{n}=j\right)=\sum_{i \in S} p\left(X_{n}=j \mid X_{0}=i\right) p\left(X_{0}=i\right)
$$

From this theory, the n-step transitions probabilities can be easily obtained by Simple matrix multiplication, for larger state space efficient of $p^{n}$ are needed.

\section{Steady-state analysis and limiting distributions}

If the Markov chain is a time-homogeneous Markov chain, so that the process is described by a single, timeindependent matrix $p_{i j}$, then the vector is called a stationary distribution (or invariant measure) if its entries $\pi_{j}$ are non-negative and sum to 1 and if it satisfies

$$
\pi_{j}=\sum_{i \in S} \pi_{i} P_{i j}
$$

Note that there is no assumption on the starting distribution; the chain converges to the stationary distribution regardless of where it begins. Such $\pi$ is called the equilibrium distribution of the chain. The long-term transition matrix, the value of $p^{n}$ approaches a fixed square matrix as $n$ increases.

\section{Applying the Markov Chain Modeling to the rainfall data}

A Markov chain is a chain of events for which the probabilities of outcomes or states depend on what has happened previously, that is, the probabilities of it being rainy or dry on a particular day depend on whether it was rainy or dry on the previous day. The assumption is that, the states 'rain' and 'dry' do not overlap and cover all probabilities. A state matrix or state vector is a row matrix which shows the probability of each state e.g. take $X=(0.150 .85)$ to mean that the probability of it being rainy on a certain day is 0.15 and probability of it being dry on that day is therefore, 0.85 . The sum of the elements of a state matrix is 1 .

The historical daily rainfall (time-sequenced) data used in this study were obtained from the Meteorology Department, Accra, Ghana, and covered the years 1980-2010, a period of 30 years, in respect of Cape Coast, Accra, Akuse, Akatsi and Keta meteorological stations located in the south eastern coast of Ghana (Fig. 1). The distance from Cape Coast (most westerly) to Keta (most easterly) is approximately $270 \mathrm{~km}$.

The data set was cleaned, that is, missing values were treated using average values of the daily rainfall for the particular month for all the years. For instance, if the rainfall value for 1 June 2009 was missing, then all the rainfall values of 1 June of all the other years from 1980 to 2010 were computed and the mean used for the value for 1 June.

The probability for rain or drought was determined for each town with their transition matrices. The Markov chain analysis was carried to find the stable future probabilities and therefore achieving the steady states.

The rainfall results (Fig. 2 to e) are the daily mean (and \pm standard error) amount of rain $(\mathrm{mm})$ on each day, over the 30 year period. The software packages, Microsoft Excel 2010 (Microsoft, Redmond, WA, USA) and Matlab (The MathWorks Inc., Natick, MA, USA) were used to analyze the data.

\section{Results and Discussion}

A preliminary look at the rainfall data collected over the 30-year period (1980-2010) in the five geographical locations, Cape Coast, Accra, Akuse, Akatsi and Keta in south eastern coast of Ghana indicates that the rainfall pattern is not evenly distributed. It is however, centralized from the months of May to September in all the five cities or towns without any certainty. From each year, the maximum amount of rainfall was derived on daily basis for the five towns, over the 30 year period 


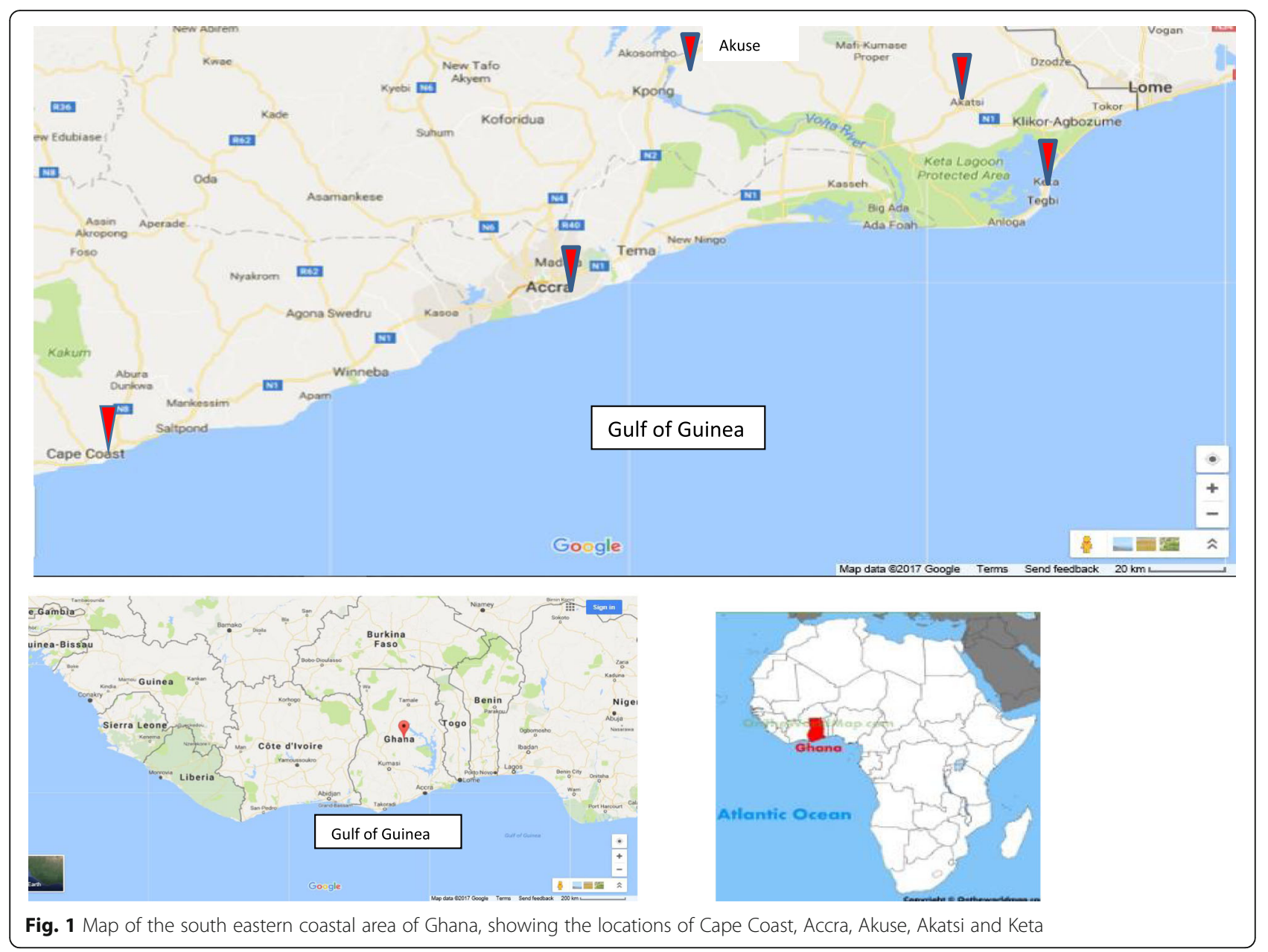

and the daily means (and \pm standard error) were then determined.

\section{Preliminary Discussions on each town}

A preliminary discussion on patterns of the mean rainfall for each location, beginning from Cape Coast, the most westerly city, proceeding eastward to Accra, Akuse, Akatsi and then Keta, is described subsequently. The towns Akuse and Akatsi are not coastal towns.

Cape-Coast is located $130 \mathrm{~km}$ west of the capital Accra. Rainy days are concentrated in the months from late April to June (Fig. 2). The city experiences a mild drought from December to March. During April to September and close to November, the mean rainfall pattern appears to be average. The highest mean daily rainfall over the 30 years occurs in May with a peak on 26th May $(16.9 \mathrm{~mm})$. The rainfall distribution approaches a normal graph.

For Accra, the periods from January to April are dry with heavy rains during a few specific days in January and March (Fig. 2b). The mean daily rain increases from March, reaching a maximum mean value in June.
The wettest months are May to September, with June 14th $(14.9 \mathrm{~mm})$ to 18 th $(17.2 \mathrm{~mm})$ recording the highest mean daily rainfalls. There are progressively drier days from August to December, with a few rainy days in October.

Akuse experiences dry spells during the months of January and February (Fig. 2c). Akuse has two low peak rainy periods; from March, increasing to June and a decrease in late July and early August. A second spell occurs in September to October. The highest daily mean amount of rainfall occurs in May (10th, $10.5 \mathrm{~mm}$ ). November and December recorded slightly more rain than January and February.

Akatsi is located $130 \mathrm{~km}$ east of Accra. The rains set in during the early part of February, rising to maximum values in May and June, then decreasing in early July (Fig. 2d). There is a second spell of a rainy period from September to early December. The later part of August experiences a little drought. The rainfall pattern around Akatsi shows two normal distributions; April to June and October to December. The highest daily mean rainfall occurs on 29th May (14.7 mm). 


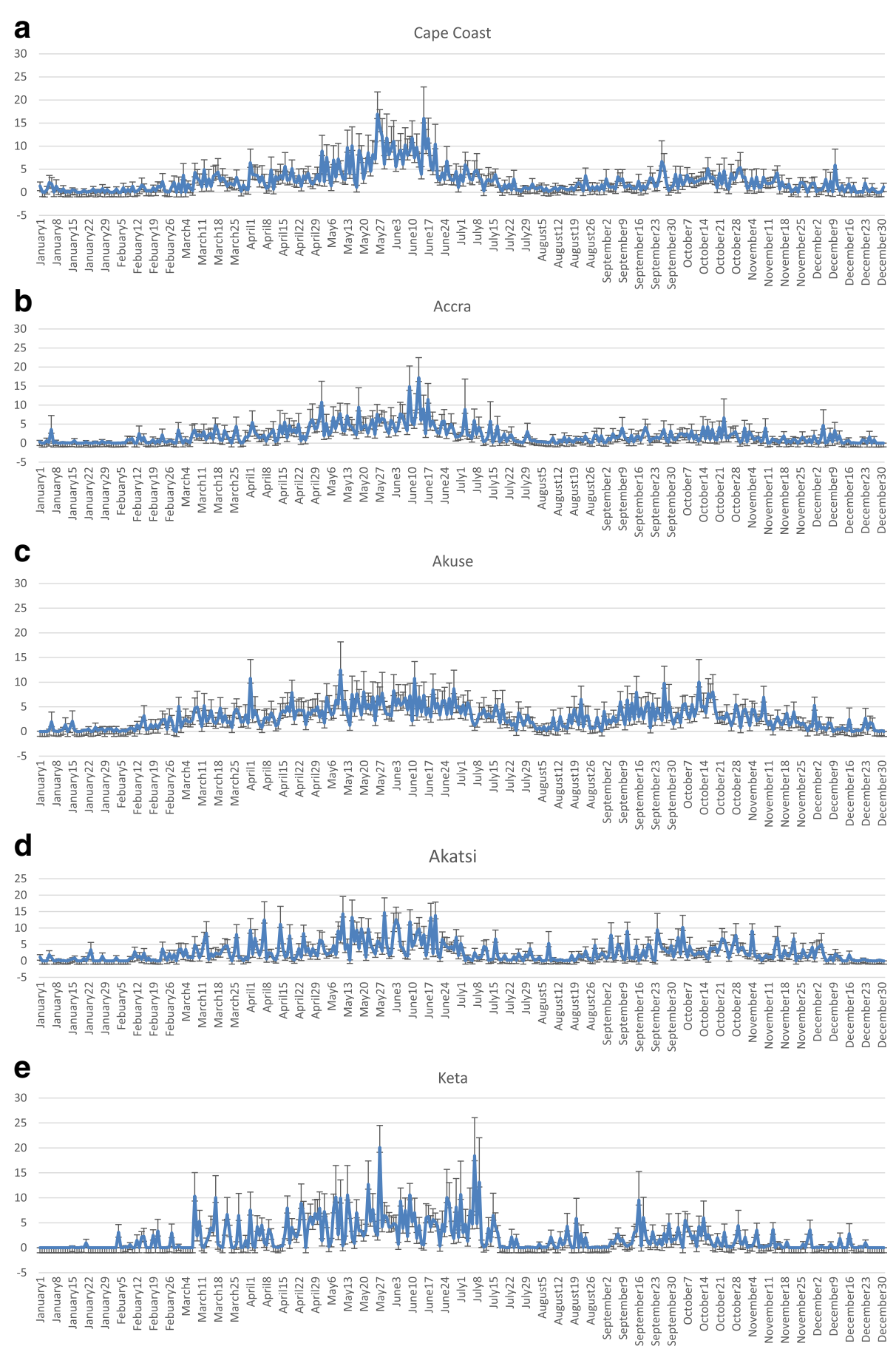

Fig. 2 a-e The daily mean ( \pm standard errors) amount of rain (mm) from January to December for the years 1980 to 2010, a period of 30 years, for the locations, Cape Coast (Fig. 2), Accra (Fig. 2b), Akuse (Fig. 2c), Akatsi (Fig. 2d) and Keta (Fig. 2e)

Keta is the most south easterly located town. The rainfall pattern of Keta is very unstable (Fig. 2e). It rains during the period March to July. January is a period of drought, with little rain or no rain occurring form 1st January to 3rd February. From July 14th to December, except for a few days in September and October, Keta experiences low rainfall. The highest mean daily rainfall occurs on May 25th $(20.1 \mathrm{~mm})$ and to 7th July $(18.4 \mathrm{~mm})$. A combined rainfall graph for all five towns of the 30 year period is shown in Fig. 3. 


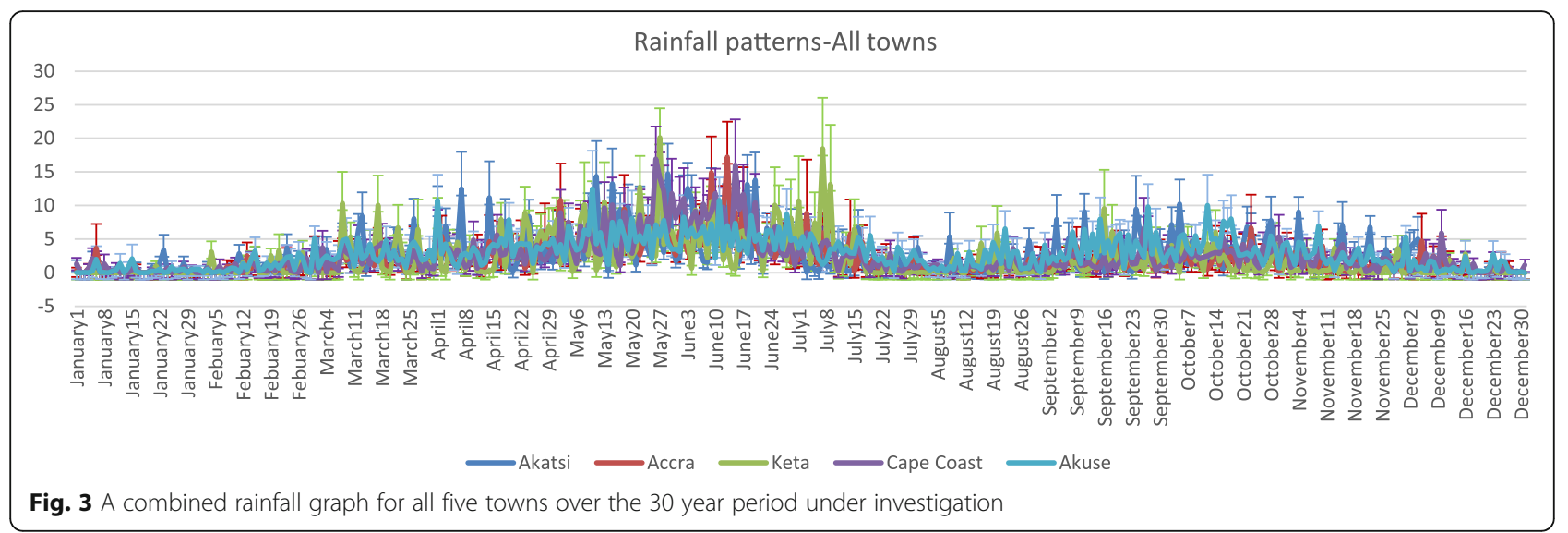

\section{Markov Chain Analysis}

Markov Chain analyses for rainfall pattern of Cape-Coast

The mean daily rainfall pattern was calculated for each day in each month. For each day a rainy day was picked to determine whether the next day is dry or rainy. The sum of the number of such days (rain or dry) was calculated and divided by the total number of days in the month. Similar computations were done for dry days. Given that it is rainy, the probability that it would be rainy a day later is given by 0.06 , and given that it is dry, the probability that it would be rainy a day later is given by 0.16 . Therefore,

$$
P=\left[\begin{array}{ll}
0.06 & 0.94 \\
0.16 & 0.84
\end{array}\right]
$$

The steady state transition matrix, the value of $p^{n}$ approaches a fixed square matrix as $n$ increases. This is represented in the Table 1 (panel, Cape Coast).

Each row $(0.1450 .855)$, from $p^{3}$, represents the long term probabilities of each state. Whatever the weather is on a given day, in the long term the probability that it will be rainy on any day is 0.145 and the probability that it will be dry on a day is 0.855 . The state matrix approaches the steady state matrix $(0.1450 .855)$ regardless of the value of the initial state matrix. The steady state matrix $(0.1450 .855)$ shows that in the future, the rainfall pattern of Cape Coast will follow the pattern of the given probability. Thus in future, the probability that it will rain on a particular day in Cape Coast is 0.145 and the probability that it will be dry on a particular in Cape Coast is 0.855 . These calculations are summarized in Table 2. The calculations of the steady state matrices for the four other towns are shown in Additional file 1: (Appendices A to D).

The steady state probability rainfall for Cape Coast indicated that, that the likelihood of rainfall is more likely in July with a probability of 0.5 as compared with other months. This indicates that the probability of both rain and drought indication is $50 \%$. Looking at data from January to December; it is clear that the rainfall increases gradually from May with the probability of 0.372 until August with the probability of 0.336 and began to decrease from September gradually until December. The maximum rainfall was recorded in the months of May to August. In general, Cape-Coast has a greater probability of rain than the other locations.

\section{Markov Chain analysis for rainfall pattern in Accra}

For Accra, given that it is rainy, the probability that it would rain a day later is given by 0.10 , and given that it is dry, the probability that it would be rainy a day later is given by 0.13 . Therefore, the transition matrix is,

$$
P=\left[\begin{array}{ll}
0.10 & 0.90 \\
0.13 & 0.87
\end{array}\right]
$$

The steady state transition matrix, the value of $p^{n}$ approaches a fixed square matrix as $\mathrm{n}$ increases. This is indicated in Table 1 (panel Accra). The transition matrix approaches the steady state matrix $(0.1260 .874)$ regardless of the value of the initial state matrix (Table 1). The steady state matrix $(0.1260 .874)$ shows that in the future, the rainfall pattern of Accra will follow the pattern of the given probability. Thus in future, the probability that it will rain on a particular day in Accra is 0.126 and the probability that it will be dry on a particular in Accra is 0.874 .

The conditional probability of either rainy or drought in a particular day for the months for Accra shows the rainfall pattern and it reveals that the rains are averagely distributed among the entire zone of Accra from April to October. The data reveals that the highest rainfall is recorded in the months May, June and October with probabilities of $0.467,0.333$ and 0.324 , respectively. The rainfall reduces in December considering the probability value of rain in December of 0.031 . 
Table 1 The steady state transition matrix for each town, the value of $p^{n}$ as $n$ increases

\begin{tabular}{|c|c|c|}
\hline \multicolumn{3}{|l|}{ Cape Coast } \\
\hline$p$ & $p^{2}$ & $p^{3}$ \\
\hline 0.060 .94 & 0.1540 .846 & 0.14460 .8554 \\
\hline 0.160 .84 & 0.1440 .856 & 0.14560 .8544 \\
\hline$p^{4}$ & $p^{5}$ & $p^{6}$ \\
\hline 0.14550 .8545 & 0.14540 .8546 & 0.14550 .8545 \\
\hline 0.14550 .8545 & 0.14550 .8545 & 0.14550 .8545 \\
\hline$p^{7}$ & $p^{8}$ & \\
\hline 0.14550 .8545 & 0.14550 .8545 & \\
\hline 0.14550 .8545 & 0.14550 .8545 & \\
\hline \multicolumn{3}{|l|}{ Accra } \\
\hline$p$ & $p^{2}$ & $p^{3}$ \\
\hline 0.100 .90 & 0.1270 .873 & 0.12620 .8738 \\
\hline 0.130 .87 & 0.1260 .874 & 0.12620 .8738 \\
\hline$p^{4}$ & $p^{5}$ & $p^{6}$ \\
\hline 0.130 .87 & 0.06910 .9309 & 0.064840 .9352 \\
\hline 0.060 .94 & 0.06420 .9358 & 0.06450 .9355 \\
\hline \multicolumn{3}{|l|}{ Akuse } \\
\hline$p$ & $p^{2}$ & $p^{3}$ \\
\hline 0.130 .87 & 0.06910 .9309 & 0.064840 .9352 \\
\hline 0.060 .94 & 0.06420 .9358 & 0.06450 .9355 \\
\hline$p^{4}$ & $p^{5}$ & $p^{6}$ \\
\hline 0.06450 .9355 & 0.06450 .9355 & 0.06450 .9355 \\
\hline 0.06450 .9355 & 0.06450 .9355 & 0.06450 .9355 \\
\hline \multicolumn{3}{|l|}{ Akatsi } \\
\hline$p$ & $p^{2}$ & $p^{3}$ \\
\hline 0.100 .90 & 0.0640 .936 & 0.06260 .9374 \\
\hline 0.060 .94 & 0.06240 .9376 & 0.06250 .9375 \\
\hline$p^{4}$ & $p^{5}$ & $p^{6}$ \\
\hline 0.06250 .9375 & 0.06250 .9375 & 0.06250 .9375 \\
\hline 0.06250 .9375 & 0.06250 .9375 & 0.06250 .9375 \\
\hline \multicolumn{3}{|l|}{ Keta } \\
\hline$p$ & $p^{2}$ & $p^{3}$ \\
\hline 0.030 .97 & 0.05910 .9409 & 0.05820 .9418 \\
\hline 0.060 .94 & 0.05820 .9418 & 0.05830 .9417 \\
\hline$p^{4}$ & $p^{5}$ & $p^{6}$ \\
\hline 0.05830 .9417 & 0.05830 .9417 & \\
\hline 0.05830 .9417 & 0.05830 .9417 & \\
\hline
\end{tabular}

\section{Markov Chain analyses for rainfall pattern in Akuse}

For Akuse, given that it is rainy, the probability that it would be rainy a day later is given by 0.13 , and given that it is dry, the probability that it would be rainy a day later is given by 0.06 . This yields the transition matrix;

$$
P=\left[\begin{array}{ll}
0.13 & 0.87 \\
0.06 & 0.94
\end{array}\right]
$$

The steady state transition matrix, the value of $p^{n}$ approaches a fixed square matrix as $n$ increases. This expressed in Table 1 (panel Akuse).

Each row (0.065 0.935, Table 1) represents the long term probabilities of each state. On any given day, in the long term the probability that it will be rainy on any day is 0.065 and the probability that it will be dry is 0.935 . The state matrix approaches a fixed matrix $(0.0650 .935)$, the steady state or stable matrix. The steady state matrix (0.065 0.935) shows that in the future, the rainfall pattern of Akuse will follow the pattern of the given probability. Thus in future, the probability that it will rain on a particular day in Akuse is 0.065 and the probability that it will be dry on a particular in Akuse is 0.935 .

Basically, the rainfall pattern of Akuse may be described as average. Following the conditional probability of either rainy or drought in a particular day for the various months in Akuse; in the long run, the rainfall is lower in January to early April. The rainfall then increases from May towards the month October, with a small dry trough in early August. The rains began to reduce again drastically from November to December. The conditional probability indicates that the highest rainfall would occur in May with probability of 0.382 ; that is, if it will rain on any particular day in May.

\section{Markov Chain analyses for rainfall pattern of Akatsi}

Given that it is rainy, the probability that it would be rainy a day later in Akatsi is given by .10, and given that it is dry, the probability that it would be rainy a day later is given by .06 . Therefore, $p$ is given by,

$$
P=\left[\begin{array}{ll}
0.10 & 0.90 \\
0.06 & 0.94
\end{array}\right]
$$

The steady state transition matrix, the value of $p^{n}$ approaches a fixed square matrix as $\mathrm{n}$ increases. This is expressed in Table 1 (panel Akatsi). The state matrix approaches the steady state matrix $(0.06250 .9375)$ regardless of the value of the initial state matrix.

The steady state matrix $(0.06250 .9375)$ shows that in the future, the rainfall pattern of Akatsi will follow the pattern of the given probability. Thus, in future, the probability that it will rain on a particular day in Akatsi is 0.0625 and the probability that it will be dry on a particular in Akatsi is 0.9375 . The observed data revealed that the rains were low, below average with risk of in the months of January to February. Gradually, the rains increase from March to July with a decrease in the daily mean amount of rain in the month of August. September to October, see the increase in the mean daily rainfall. 
Table 2 Rainfall pattern of Cape Coast

\begin{tabular}{|c|c|c|c|}
\hline Month & Initial matrix (p) & Long term probability matrix & $\begin{array}{l}\text { Probability of either } \\
\text { 'rain' or 'dry' on a day }\end{array}$ \\
\hline January & $\left(\begin{array}{ll}0.06 & 0.94 \\
0.16 & 0.84\end{array}\right)$ & $p^{8}=\left(\begin{array}{ll}0.145 & 0.854 \\
0.145 & 0.854\end{array}\right)$ & 0.1450 .854 \\
\hline February & $\left(\begin{array}{ll}0.14 & 0.86 \\
0.07 & 0.93\end{array}\right)$ & $p^{6}=\left(\begin{array}{ll}0.075 & 0.923 \\
0.075 & 0.923\end{array}\right)$ & 0.0750 .923 \\
\hline March & $\left(\begin{array}{ll}0.23 & 0.77 \\
0.06 & 0.94\end{array}\right)$ & $p^{9}=\left(\begin{array}{ll}0.072 & 0.928 \\
0.072 & 0.928\end{array}\right)$ & 0.0720 .928 \\
\hline April & $\left(\begin{array}{ll}0.29 & 0.71 \\
0.42 & 0.58\end{array}\right)$ & $p^{6}=\left(\begin{array}{ll}0.280 & 0.720 \\
0.280 & 0.720\end{array}\right)$ & 0.2800 .720 \\
\hline May & $\left(\begin{array}{ll}0.23 & 0.77 \\
0.30 & 0.70\end{array}\right)$ & $p^{8}=\left(\begin{array}{ll}0.372 & 0.628 \\
0.372 & 0.628\end{array}\right)$ & 0.3720 .628 \\
\hline June & $\left(\begin{array}{ll}0.60 & 0.40 \\
0.27 & 0.43\end{array}\right)$ & $p^{13}=\left(\begin{array}{ll}0.403 & 0.597 \\
0.403 & 0.597\end{array}\right)$ & 0.4030 .597 \\
\hline July & $\left(\begin{array}{ll}0.45 & 0.55 \\
0.55 & 0.45\end{array}\right)$ & $p^{7}=\left(\begin{array}{ll}0.50 & 0.50 \\
0.50 & 0.50\end{array}\right)$ & 0.500 .50 \\
\hline August & $\left(\begin{array}{ll}0.23 & 0.77 \\
0.39 & 0.61\end{array}\right)$ & $p^{8}=\left(\begin{array}{ll}0.336 & 0.664 \\
0.336 & 0.664\end{array}\right)$ & 0.3360 .664 \\
\hline September & $\left(\begin{array}{ll}0.33 & 0.67 \\
0.10 & 0.90\end{array}\right)$ & $p^{10}=\left(\begin{array}{ll}0.130 & 0.870 \\
0.130 & 0.870\end{array}\right)$ & 0.1300 .870 \\
\hline October & $\left(\begin{array}{ll}0.32 & 0.68 \\
0.42 & 0.58\end{array}\right)$ & $p^{7}=\left(\begin{array}{ll}0.382 & 0.618 \\
0.382 & 0.618\end{array}\right)$ & 0.3820 .610 \\
\hline November & $\left(\begin{array}{ll}0.23 & 0.77 \\
0.17 & 0.83\end{array}\right)$ & $p^{6}=\left(\begin{array}{ll}0.182 & 0.820 \\
0.182 & 0.820\end{array}\right)$ & 0.1820 .820 \\
\hline December & $\left(\begin{array}{ll}0.03 & 0.97 \\
0.13 & 0.87\end{array}\right)$ & $p^{7}=\left(\begin{array}{ll}0.118 & 0.882 \\
0.118 & 0.882\end{array}\right)$ & 0.1180 .882 \\
\hline
\end{tabular}

According to the conditional probability of either rainy or drought in a particular day for the various month in Akatsi, in June, it shows clearly that the probability of rains occurring has equal chance as that of drought or no rain (Probability of 50\%). On average, Akatsi seems to have a higher probability of it being rainy on any day than the four other towns.

\section{Markov Chain analyses for rainfall pattern of Keta}

For Keta, given that it is rainy, the probability that it would be rainy a day later is given by .03 , and given that it is dry, the probability that it would be rainy a day later is given by .06. This is given as,

$$
P=\left[\begin{array}{ll}
0.03 & 0.97 \\
0.06 & 0.94
\end{array}\right]
$$

The steady state transition matrix, the value of $p^{n}$ approaches a fixed square matrix as $n$ increases, and it is expressed in Table 1 (panel Keta). The state matrix approaches the steady state matrix $(0.058$ 0.942) and shows that in the future, the rainfall pattern of Keta will follow the pattern of the given probability. Thus in future, the probability that it will rain on a particular day in Keta is 0.058 and the probability that it will be dry on a particular in Keta is 0.942 .
The observed data indicates that, the rainfall pattern of Keta is not favourable; there is a higher probability of drought. Looking at the conditional probability values of either rainy or drought in a particular day for the various month in this town, it shows clearly that rainfall may occur a little in the month of April to May with even a downward trend. August and September also have a little rain where the rest of the month is likely not to experience any rain.

The Markov chain analysis for the various towns showed that, the probability of rain in each town varies day by day. Also the long term probability differs from town to town. Observations made on the long term probability values for each town showed that all the five locations tended to be dry. That is, all locations experience more dry days than rainy days. This is because in each case, the long term probability of rain falling on any day is generally low (Table 3 ). We also observed that from Keta (most easterly), through Accra to Cape Coast (most westerly), the maximum rainfall probability generally increases from east to west.

Until recently, rainfall pattern assessment has been a challenging task among rainfall researchers and professionals. There are many rainfall tools that have been developed around the world and are commonly used to quantify rainfall conditions. It was found that in most cases, Markov chain analysis developed for a specific 
Table 3 Maximum rainfall and Maximum probability rainfall

\begin{tabular}{lllll}
\hline Town & Month & Maximum Daily Mean Rainfall $(\mathrm{mm})$ & Month & $\begin{array}{c}\text { Maximum } \\
\text { Probability }\end{array}$ \\
\hline Cape Coast & May & 16.9 & May \& July & $0.372 \& 0.50$ \\
Accra & June & 17.2 & May & 0.467 \\
Akuse & May & 12.5 & May & 0.382 \\
Akatsi & June & 14.7 & June & 0.50 \\
Keta & May-July & $20.1 \& 18.4$ & May-Sept. & $0.215 \& 0.277$ \\
\hline
\end{tabular}

region, could not be directly applied to other regions due to inherent complexity of rainfall phenomena, different hydro-climatic conditions and catchment characteristics. Markov chain analysis has been employed to assess different climatic regions around the world (Robertson et al. 2004; Paulo and Pereira, 2007). Data bases including the University of California Irvine (CHRS) indicates a trend towards drier weather in Ghana (https:/www.ncdc.noaa.gov/ cdo-web/datasets). However, no such work has been conducted with Markov chain to show rainfall patterns and published from within Ghana.

In this investigation, an employment of Markov chain analysis for modeling historical daily rainfall within the south eastern coast of Ghana has been done. Daily mean rainfall values recorded in south eastern coast during 1980-2010 were used in this study to investigate how well the Markov chain method was capable of defining rainfall conditions. The study showed that Markov chain analysis is a good method in predicting patterns of rainfall and detecting similarities in historical rainfall. The summary of the highest recorded rainfall from the time series data and the highest expected rainfall probability for the month is indicated in the Table 3.

\section{Conclusions}

This report aimed to classify and assessed annual rainfall over the south eastern coast of Ghana into rainy and drier groups. It was determined that a Markov chain analysis classifies this pattern. The steady state transition matrices and the steady state probability vectors were computed for each town and each month over a 30-year period (1980-2010). It was found that, the rainy or dry season patterns observed using the monthly steady state rainfall vectors tended to coincide with the monthly rainfall time series trajectory. That is, the highest mean daily rainfall occurring from the time series data corresponds with the computed maximum probability from Markov chain analysis. For Accra, for example, the rainy season was observed to be in the month of May to June and September to October. The probability of rainfall generally tended to increase from east to west along the south eastern coast of Ghana. This work could be helpful to agro industries, agricultural insurance practitioners and other business organizations, to enable them plan their activities accordingly; preparing the land and planting of seed crops, and offer advice to their clients in terms of investments. The study also demonstrated the practical application of the Markov chain analysis to meteorological data, the first of its kind in Ghana.

\section{Additional file}

Additional file 1: Supplementary material: Appendix A, B, C, D, E. (DOCX $135 \mathrm{~kb}$ )

\section{Acknowledgements}

The authors thank the Ministry of Agriculture and Meteorology Department, Ghana for allowing access to the rainfall data.

\section{Authors' contributions}

MT and FTO developed the idea. Data was collected and analysed by MT, FTO, DA and DAA. Manuscript writing was led by DAA and DA. All four authors approved the final manuscript.

\section{Competing interests}

The authors declare that they have no competing interests.

\section{Publisher's Note}

Springer Nature remains neutral with regard to jurisdictional claims in published maps and institutional affiliations.

\section{Author details}

${ }^{1}$ Department of Mathematics, Kwame Nkrumah University of Science and Technology, Kumasi, Ghana. ${ }^{2}$ Current address: Department of Mathematics, E. P. College of Education, PO Box AM 12, Amedzofe, VR, Ghana. ${ }^{3}$ School of Basic and Biomedical Sciences, University of Health and Allied Sciences, PMB, $31 \mathrm{Ho}$, VR, Ghana.

Received: 27 April 2017 Accepted: 28 July 2017

Published online: 18 August 2017

\section{References}

Cai W, Wang G, Santoso A, McPhaden MJ, Wu L, Jin F-F, Timmermann A, Collins M, Vecchi G, Lengaigne M, England MH, Dommenget D, Takahashi K, Guilyardi E (2015) Increased frequency of extreme La Niña events under greenhouse warming. Nat Clim Chang 5:849-859. doi:10.1038/nclimate2492

Climate Change Knowledge portal: http://sdwebx.worldbank.org/climateportal/ index.cfm?page $=$ country_historical_ climat e\&ThisCCode $=\mathrm{GHA}$

Coffie ED (2010) The Rains Are Here Again: Whose Responsibility Is It to Protect Us? Ghanaweb.com. http://www.ghanaweb.com/GhanaHomePage/features/ TheRains-Are-Here-Again-Whose-Responsibility-Is-It-To-Protect-Us-184733

Dore MHI (2005) Climate change and changes in global precipitation patterns: What do we know? Environ Int 31(8):1167-1181

Environmental Protection Agency, Ghana (2000) Climate Change Impacts, Vulnerability and Adaptation Assessments in Ghana, 162 pp 4 pdf. 1st National Communication of Ghana to the United Nation Framework Convention on Climate Change. Environmental Protection Agency, UNFCCC, Cambridge. http://unfccc.int/resource/ docs/natc/ghanc3.pdf 
Fletcher CG, Matthews L, Andrey J, Saunders A (2015) Projected Changes in MidTwenty-First-Century Extreme Maximum Pavement Temperature in Canada. J Appl Meteor Clim 55:961-974

Gabriel KR, Neumann J (1962) A Markov chain model for daily rainfall occurrence at Tel Aviv. Q J R Meteorol Soc 88:90-95

Gregory JM, Wigley TML, Jones PD (1993) Application of Markov models to areaaverage daily precipitation series and inter-annual variability in seasonal totals. Clim Dyn 8(6):299-310

Gringorten II (1996) A stochastic model of the frequency and duration of weather events. J Clim Appl Meteorol 5:606-624

Groisman PY, Knight RW, Easterling DR, Karl TR, Hegerl GC, Razuvaev VN (2005) Trends in intense precipitation in the climate record. J Clim 18:1326-1350

Haan CT, Allen DM, Street JO (1976) A Markov chain model of daily rainfall. Water Resour Res 12(3):443-449

Hansen J, Ruedy R, Sato M, Lo K (2010) Global Surface Temperature Change. Rev Geophys 48(4) RG4004)):1-29

Hayhoe HN (2000) Improvements of stochastic weather data generators for diverse climates. Clim Res 14:75-87

IPCC 2014. Settele J, Scholes R, Betts R, Bunn S, Leadley P, Nepstad D, Overpeck TK, Taboada MA. Terrestrial and Inland Water Systems. In: Climate Change 2014: Impacts, Adaptation and Vulnerability. Part A: Global and Sectoral Aspects. Contribution of Working Group II to the Fourth Assessment Report of the Intergovernmental Panel on Climate Change. https://www.ipcc.ch/pdf/ assessment-report/ar5/wg2/WGIIAR5-Chap4_FINAL.pdf

Kharin W, Zwiers FW, Zhang X (2005) Inter-comparison of near-surface temperature and precipitation extremes in AMIP-2 simulations, re-analyses, and observations. J Clim 18:5201-5223. doi:10.1175/JCLI3597

Kottegoda NT, Natale L, Raiteri E (2004) Some considerations of periodicity and persistence in daily rainfalls. J Hydrol 296:23-37

Liu X, Ren L, Yuan F, Yang B, Nanjing PR (2009) Meteorological drought Forecasting using Markov Chain model. In: 11th International Conference on Environmental Science and Information Application Technology, Chania, Crete, Greece, pp 23-26 http://toc.proceedings.com/18229webtoc.pdf

Lohani VK, Loganathan GV (1997) An early warning system for drought management using the Palmer drought index. J Am Water Resour Assoc 33:1375-1386

Lohani VK, Loganathan GV, Mostaghimi S (1998) Long-term analysis and short-term forecasting of dry spells by Palmer Drought Severity Index. Nord Hydrol 29(1):21-40

Meteorological Services Agency of Ghana. http://www.meteo.gov.gh/website/\# Nelson W, Agbey SND (2005) Climate change and poverty linkages. In: Allotey J, Mensah $L$ (eds) Ghana climate change impacts, vulnerability and adaptation assessments, under the Netherlands climate assistance programme. Accra, Ghana: Environmental Protection Agency, Chapter 5, pp 169-206

Papalexiou SM, Koutsoyiannis D, Makropoulos C (2013) How extreme is extreme? An assessment of daily rainfall distribution tails. Hydrol Earth Syst Sci 17(2):851-862

Papoulis A (1984) Probability, Random Variables, and Stochastic Processes, 2nd edn. McGraw-Hill, New York

Paulo AA, Pereira LS (2007) Prediction of SPI drought class transitions using Markov chains. Water Resour Manag 21(10):1813-1827

Racsko PL, Szeidl L, Semenov M (1991) A series approach to local stochastic weather models. Ecol Model 57:27-41

Raiford JP, Aziz NM, Khan AA, Powell DN (2007) Rainfall Depth- Duration- Frequency Relationships for South Carolina, North Carolina, and Georgia. Am J Environ Sci 3(2):78-84

Robertson AW, Kirshner S, Smyth P (2004) Downscaling of daily rainfall occurrence over northeast Brazil using a hidden Markov model. J Clim 17(22):4407-4424

Shannon CE (July-October 1948). A Mathematical Theory of Communication (PDF). Bell Syst Tech J 27 (3): 379-423. doi:10.1002/j.1538-7305.1948.tb01338.x

Srikanthan R, McMahon TA (2005) Automatic Evaluation of Stochastically Generated Rainfall Data, Conference Paper. Aust J Water Resour 8(2):195-201

Stern RD, Coe R (1984) A model fitting analysis of daily rainfall data. J R Stat Soc A 147(1):1-34

University of California Irvine Center for Hydrometeorology and Remote Sensing (CHRS) (https:/www.ncdc.noaa.gov/cdr/atmospheric/precipitation-persiann-cdr)

Villarini G, Smith JA, Napolitano F (2010) Nonstationary modeling of a long record of rainfall and temperature over Rome. Adv Water Resour 33(10):1256-1267

Westral S, Alexander LV, Zwiers FW (2013). Global Increasing Trends in Annual Maximum Daily Precipitation. J Climate, 26: 3904-3918. American Meteorological Society http://dx.doi.org/10.1175/JCLI-D-12-00502.1
Wilks DS (1999) Inter annual variability and extreme-value characteristics of several stochastic daily precipitation models. Agric For Meteorol 93(3):153-169

Wilks DS, Wilby RL (1999) The weather generation game: a review of stochastic weather models. Prog Phys Geogr 23(3):329-357

von Storch H, Zwiers FW (1999) Statistical Analysis in Climatology. Cambridge University Press, Cambridge, pp 197-213 https://pdfs.semanticscholar.org /d457/3b4307d80e5b9f1845770c226759fb331023.pdf

\section{Submit your manuscript to a SpringerOpen ${ }^{\circ}$ journal and benefit from:}

- Convenient online submission

- Rigorous peer review

- Open access: articles freely available online

- High visibility within the field

- Retaining the copyright to your article

Submit your next manuscript at springeropen.com 